\title{
Intact Aggrecan and Fragments Generated by Both Aggrecanse and Metalloproteinase-Like Activities Are Present in the Developing and Adult Rat Spinal Cord and Their Relative Abundance Is Altered by Injury
}

\author{
Michele L. Lemons, ${ }^{1,3}$ John D. Sandy, ${ }^{4}$ Douglas K. Anderson, ${ }^{1,2,3,5}$ and Dena R. Howland ${ }^{1,3}$ \\ Departments of ${ }^{1}$ Neuroscience and ${ }^{2}$ Neurological Surgery, University of Florida College of Medicine, Gainesville, Florida \\ 32610-0244, ${ }^{3} E v e l y n$ F. and William L. McKnight Brain Institute of The University of Florida, Gainesville, Florida 32611, \\ ${ }^{4}$ Shriners Hospital for Crippled Children and College of Medicine, University of South Florida, Tampa, Florida 33612, and \\ 5 Malcom Randall Veterans Affairs Medical Center, Gainesville, Florida 32608
}

Aggrecan is a large proteoglycan (PG) that has been grouped with different PG families on the basis of its physical characteristics. These families include the chondroitin sulfate PGs, which appear to inhibit the migration of cells and axons during development. Although aggrecan has been studied primarily in cartilage, in the present study, tissue samples from developing, mature, and injured-adult rat spinal cords were used to determine whether aggrecan is present in the mammalian spinal cord. By the use of Western blot analysis, tissues were probed with aggrecan-specific antibodies (ATEGQV, TYKHRL, and LEC-7) and aggrecan-specific neoepitope antibodies (NITEGE, FVDIPEN, and TFKEEE) to identify full-length aggrecan and several fragments. Unlike many other aggrecan gene family members, aggrecan species were similar in embryonic day 14, postnatal day 1, and adult spinal cords. Spinal cord injury caused significant decreases in aggrecan. Partial recovery in some aggrecan species was evident by 2 weeks after injury. The presence of specific aggrecan neoepitopes suggested that aggrecan is cleaved in the spinal cord by both a disintegrin and metalloproteinase thrombospondin (also known as aggrecanase) and metalloproteinase-like activities. Many aggrecan species found in the spinal cord were similar to species in cartilage. Additional antibodies were used to identify two other aggrecan gene family members, neurocan and brevican, in the adult spinal cord. These studies present novel information on the aggrecan core protein species and enzymes involved in aggrecan cleavage in vivo in the rat spinal cord throughout development and after injury. They also provide the basis for investigating the function of aggrecan in the spinal cord.

Key words: spinal cord; spinal cord injury; development; aggrecan; aggregating proteoglycan; chondroitin sulfate proteoglycan; metalloproteinase; aggrecanase; neurocan; brevican
Aggrecan is a large proteoglycan that has been characterized predominantly as a component of the extracellular matrix of cartilage (Doege et al., 1987, 1991; Hascall et al., 1994). It also, however, is present in the developing brain (Schwartz et al., 1993; Milev et al., 1998b) and has been identified recently in the adult brain (Milev et al., 1998b). It is the largest of four molecules that form a family of proteoglycans that have been identified by several names: the lecticans (Schwartz et al., 1996), the aggrecan gene family (Schwartz et al., 1999), and the hyaluronan-binding proteoglycans (Milev et al., 1998b). The other three family members are neurocan, brevican, and versican, all of which have also been identified in the CNS. Despite a number of structural similarities between these four proteoglycans, on the basis of their differential expression in the brain (Milev et al., 1998b), it is likely that they have distinct functions in the CNS.

\footnotetext{
Received Sept. 27, 2000; revised April 2, 2001; accepted April 17, 2001.

This study was supported by the State of Florida Brain and Spinal Cord Injury Rehabilitation Trust Fund, the Department of Veterans Affairs, the C. M. and K. E. Overstreet Endowment, and the Shriners of North America. We thank Wilbur O'Steen and G. Othel O'Steen for their invaluable technical assistance during surgery and with animal care and Troy Howell for his invaluable technical assistance with Western blot quantification.

Correspondence should be addressed to Dr. Dena R. Howland, Department of Neuroscience, University of Florida and McKnight Brain Institute, 100 Newell Drive, Building 59, Room L1-100G, Box 100244, Gainesville, FL 32610-0244. Email: howland@mbi.ufl.edu.

Copyright (C) 2001 Society for Neuroscience $\quad 0270-6474 / 01 / 214772-10 \$ 15.00 / 0$
}

There is indirect evidence that this family of proteoglycans modulates cell adhesion, migration, and axonal outgrowth in the developing CNS (Schwartz et al., 1996; for review, see Yamaguchi, 2000). Because aggrecan, neurocan, brevican, and versican core proteins can all be substituted with chondroitin sulfate (CS) glycosaminoglycan (GAG) chains, they are all members of the larger family of CSPGs. Their potential for CS substitution, however, varies markedly in that aggrecan may carry up to $100 \mathrm{CS}$ chains, whereas human neurocan, brevican, and versican may be maximally substituted with 23,11 , and 4 CS chains, respectively.

Although recent studies suggest that CSPGs inhibit regeneration after spinal cord injury (SCI) (Gates et al., 1996; Fitch and Silver, 1997; Lemons et al., 1999), there is little information on the presence of aggrecan in the adult spinal cord (Asher et al., 1995). Furthermore, no study has determined whether specific aggrecan fragments, characteristic of cartilage (Lark et al., 1995a,b,c, 1997; Sandy and Lark, 1999), also might be present in the CNS. Thus, in the current study, we have used Western blot analysis and a panel of monospecific antibodies, as well as neoepitope antisera against specific degradation products, to identify and characterize aggrecan in developing, adult, and injured-adult rat spinal cords. Our data show that the full-length aggrecan protein core $(\sim 350 \mathrm{kDa})$ is a normal constituent of the spinal cord in the embryo and throughout life. We also show the presence of well characterized aggrecan fragments in spinal cord 
tissue using neoepitope antibodies. In cartilage, two of the fragments studied (NITEGE and TFKEEE) are generated by the action of ADAMTS activity (first described as "aggrecanase") on aggrecan (Sandy et al., 1995). The third fragment [globular domain 1 (G1)-VDIPEN] results primarily from the action of metalloproteinases (MMPs) or cathepsin B (CatB) (Lark et al., 1995c; Mort et al., 1998). Overall, there is no striking difference between the aggrecan core protein products seen in the spinal cord during development and adulthood. Spinal cord injury, however, significantly decreases aggrecan content. Thus, this study provides the first analysis of aggrecan core structure and its degradation products in the mammalian spinal cord and provides a framework for the investigation of the function of these species in this tissue.

\section{MATERIALS AND METHODS}

Hemisection spinal cord injury. Female adult Long-Evans rats were anesthetized with an intraperitoneal injection of sodium pentobarbital $(35 \mathrm{mg} / \mathrm{kg})$. All animals were given an antibiotic, penicillin $\mathrm{G}$ procaine (30,000 U/250 gm; Phoenix Pharmaceutical, Inc., St. Joseph, MO), subcutaneously for $7 \mathrm{~d}$, beginning on the day of surgery. Surgical procedures were performed using sterile techniques and on a warming pad. The low thoracic spinal cord was exposed by a laminectomy, and the dura mater was slit. Iridectomy scissors were used to make three cuts in the spinal cord at $\sim$ T13. Two unilateral hemisections $2-3 \mathrm{~mm}$ apart were made, and a third cut connected the medial aspects of the hemisections. Gentle aspiration was used to lift out the tissue isolated by the cut and any remaining tissue to make a complete hemisection. If the edges of the dura matter remained intact after hemisection injury, the dura matter was sutured. The muscle and skin were closed in layers. Rats recovered in a veterinary intensive care unit and were rehydrated immediately after surgery with subcutaneous injections of $3 \mathrm{ml}$ of saline. The bladders of the rats were manually expressed twice daily until bladder function returned.

Tissue preparation. Animals [3 timed-pregnant, 7 postnatal day 1 (PND1), 15 normal adult, and 25 spinal cord-injured adult rats] were deeply anesthetized with an overdose of sodium pentobarbital ( $>50$ $\mathrm{mg} / \mathrm{kg}$ ). An ovariohysterectomy procedure was performed on timedpregnant animals at $14 \mathrm{~d}$ after conception. The intact uterus was removed and placed on ice. The embryonic day 14 (E14) spinal cords were kept cold while the spinal cords were carefully dissected and the dura matter was removed under a microscope. The spinal cords of PND1 rats were similarly removed with the aid of a dissecting microscope. The spinal cords of normal adults or spinal cord-injured adults were removed after a laminectomy procedure. A large laminectomy was made from T10 through L2. Twenty-five millimeters of the exposed spinal cord were quickly removed by severing the roots and cutting the spinal cord. The injured spinal cords were blocked into five $5 \mathrm{~mm}$ pieces with the middle piece containing the lesion epicenter. Each $5 \mathrm{~mm}$ piece approximated one spinal segment. Thus, in addition to the lesion at T13, $10 \mathrm{~mm}$ of tissue above and below the lesion epicenter was collected and referred to as "tissue rostral or caudal to the lesion," respectively. Only tissue from the lesion blocks was used for the quantitative aspects of the study. All harvested spinal cords (E14, PND1, adult, and injured adult) were immediately frozen in liquid nitrogen and maintained at $-70^{\circ} \mathrm{C}$ until processed. Tissue was then quickly thawed, rinsed with cold phosphatebuffered solution (PB), and placed into a cold proteinase inhibitor solution. The proteinase inhibitor solution consisted of "total proteinase inhibitor cocktail" (Boehringer Mannheim, Indianapolis, IN) in 0.1 м PB, pH 7.4, with $5 \mathrm{~mm}$ iodoacetic acid, $0.1 \mathrm{~mm}$ 4-(2-aminoethyl)benzenesulphonyl flouride, $1 \% 3$-[(cholamidopropyl)dimethylammonio]-1-propane-sulfonate, $1 \mu \mathrm{g} / \mathrm{ml}$ pepstatin A, $50 \mathrm{~mm}$ sodium acetate, $5 \mathrm{~mm}$ benzamidine hydrochloride hydrate, $5 \mathrm{~mm}$ phenylmethylsulfonyl fluoride, and $10 \mathrm{~mm} \mathrm{~N}$ ethylmaleimide (Sigma). The tissue was then quickly cut into $5 \mathrm{~mm}$ pieces while in the proteinase inhibitor solution, blotted dry, weighed, and placed into $1.5 \mathrm{ml}$ tubes with $15 \mathrm{vol}(1.6 \mu \mathrm{l} / \mathrm{mg}$ of tissue $)$ of cold extractant solution (proteinase inhibitor solution containing $4 \mathrm{~m}$ guanidine hydrochloride, $\mathrm{pH}$ 7.6). Each sample was homogenized, using a prechilled "tissue tearer" (from Biospec Products, Inc.), for 3-5 sec and extracted overnight at $4^{\circ} \mathrm{C}$. The samples were clarified by centrifugation at $14,000 \times g$ for $90 \mathrm{~min}$ at $4^{\circ} \mathrm{C}$. A floating layer of insoluble material (myelin) was removed. The clear extracts were precipitated overnight with $3 \mathrm{vol}$ of cold ethanol and $5 \mathrm{~mm}$ sodium acetate at $0^{\circ} \mathrm{C}$. Precipitated proteins (including the proteoglycans) were collected by centrifugation for $1 \mathrm{hr}$ at $14,000 \times g$ at $4^{\circ} \mathrm{C}$. Ethanol was removed, and the tissue pellet was resuspended in, and chondroitinasedigested with, $125 \mu \mathrm{l}$ of $0.9 \mathrm{U}$ of purified chondroitinase ABC (Sigma) in 1 $\mathrm{ml}$ of buffer (50 mM sodium acetate, $50 \mathrm{~mm}$ Tris hydrochloride, and $10 \mathrm{~mm}$ EDTA, pH 8) for $3 \mathrm{hr}$ at $37^{\circ} \mathrm{C}$.

Protein concentration was determined using a modification of a published method. Briefly, in a 96-well plate, samples were assayed with 250 $\mu \mathrm{l}$ of Bradford reagent (Sigma) and a plate reader (programmed to read at $595 \mathrm{~nm}$ ). A dilution series $(0-10 \mu \mathrm{g})$ of bovine serum albumin (Sigma) was also assayed to generate a standard curve. The protein concentration of each sample was calculated on the basis of the standard curve. On average, $57 \mu \mathrm{g}$ of protein was loaded per lane for the qualitative aspects of this study. The high protein loading was done to expose the complete spectrum of all aggrecan core species present in each tissue for the qualitative aspects of the study. For the quantitative aspects of the study, lanes were loaded on the basis of wet tissue weight. Thus, each lane was loaded with a microliter amount equal to $12.7 \%$ of the wet weight.

Electrophoresis. Chondroitinase-digested samples were mixed with sample buffer (Novex $2 \times$ sample buffer containing $800 \mathrm{~mm}$ D,Ldithiothreitol and $3 \mathrm{M}$ urea) and heated at $100^{\circ} \mathrm{C}$ for $5 \mathrm{~min}$. The samples were loaded on a 10 -well, 1.5-mm-thick, 4-12\% SDS-PAGE gradient gel (Novex, San Diego, CA). The gels were run at $125 \mathrm{~V}$ for $85 \mathrm{~min}$ in electrode buffer ( $25 \mathrm{~mm}$ Tris base, $192 \mathrm{~mm}$ glycine, and $0.1 \%$ SDS). See Blue prestained molecular weight markers (Novex) and biotinylated broad-range molecular weight markers (Bio-Rad, Hercules, CA) were used as standards. Purified aggrecan from rat chondrosarcoma (RCS) chondroitinase-digested was used as a positive control [this material contains full-length aggrecan and several of its naturally occurring degradative products (Sandy et al., 1995)]. Aggrecan degradative products from RCS are similar to those degradative products typically found in cartilage (Sandy et al., 1995, 2000).

Transfer and immunoblotting. Gels that were processed for the presence of aggrecan were transferred onto a $0.45 \mu \mathrm{m}$ nitrocellulose membrane in a Bio-Rad Transfer Unit filled with transfer buffer (25 mM Tris base, $192 \mathrm{~mm}$ glycine, and 20\% methanol). These gels were transferred with $100 \mathrm{~V}$ for $1 \mathrm{hr}$ at room temperature or $30 \mathrm{~V}$ overnight on ice. Gels that were processed for the presence of brevican were also transferred onto a $0.45 \mu \mathrm{m}$ nitrocellulose membrane using a transfer buffer that did not contain methanol ( $25 \mathrm{~mm}$ Tris base and $192 \mathrm{~mm}$ glycine $)$ with $150 \mathrm{~mA}$ for $2 \mathrm{hr}$. After transfer, all membranes were rinsed twice for $5 \mathrm{~min}$ each. The first rinse was with $20 \mathrm{~mm}$ Tris-buffered saline containing $0.5 \%$ Tween and $137 \mathrm{~mm}$ sodium chloride at $\mathrm{pH} 7.6$ (TBS-T20), and the second was with $1 \%$ nonfat dry milk in TBS-T20. The membranes were then blocked in 5\% nonfat dry milk (Carnation) in TBS-T20, followed by a 45 min incubation with one of several primary antibodies [anti-ATEGQV, TYKHRL, NITEGE, FVDIPEN, TFKEEE, globular domain 3 (G3), LEC-7, and G1] diluted in TBS-T20 containing $1 \%$ nonfat dry milk (each primary was diluted at 1:3000 except for FVDIPEN that was diluted at 1:1000). The use of these antibodies has been described in detail previously (Lark et al., 1995a,b,c; Sandy et al., 1995) and is described in more detail below. Membranes were washed with TBS-T20 quickly two times and then three times for $10 \mathrm{~min}$ each. Membranes were then incubated with goat anti-rabbit peroxidase-labeled antibodies (Vector Laboratories, Burlingame, CA; 1:5000) in TBS-T20 containing 1\% nonfat dry milk for $30 \mathrm{~min}$. The portion of the nitrocellulose membrane that contained biotinylated markers was cut out and run separately from the portion of the membrane that contained spinal cord tissue. We have found that the strepavidin-horseradish peroxidase (HRP) used to label the biotinylated molecular weight markers can nonspecifically bind to lanes containing spinal cord tissue. Thus, the portion of the membrane with biotinylated markers was cut and separately incubated with strepavidin-HRP (Vector Laboratories; 1:5000) for $30 \mathrm{~min}$. Two negative controls were done: (1) the membrane was not incubated with the primary antibody, and (2) the membrane was incubated with the primary antibody that had been preincubated with aggrecan (10 $\mu$ l of antibody with $0.1 \mathrm{mg}$ of aggrecan dissolved in $100 \mu \mathrm{l}$ of distilled water). All membranes were rinsed in TBS-T20 as described above and incubated with a chemiluminescent marker, ECL (Amersham, Arlington Heights, IL), for $1 \mathrm{~min}$. Film exposure times ranged from $15 \mathrm{sec}$ to $3 \mathrm{~min}$ to generate suitable images for the qualitative aspects of the study. Exposure times were consistent $(30 \mathrm{sec})$ for all films used for the quantitative aspects of the study. Any film-to-film variation was normalized by the use of purified RCS (1 $\mu \mathrm{g}$ of core protein) in duplicate on each gel.

Primary antibodies. The epitope locations for the seven antibodies used 
Figure 1. Aggrecan antibody binding. Illustration of the seven aggrecan antibody-binding epitopes (bolded), several known aggrecanase cleavage sites (underlined), and one MMP cleavage site (double underlined). Four of the antibodies (ATEGQV, G1, TYKHRL, and LEC-7) label both fulllength aggrecan and aggrecan degradative products. Three neoepitope antibodies (NITEGE, FVDIPEN, and TFKEEE) label sites that are exposed only after enzymatic cleavage. The neoepitope antibodies are marked by an asterisk. All sequences shown are human and are conserved in the rat except that the TFKEEE antisera detects TFREEE in rat. The expected cleavage sites that would produce the $50 \mathrm{kDa}$ KEEE-positive species (see Fig. 2, lane 12) are also indicated. Residue numbers are shown for C-terminal neoepitopes. Circles indicate the three globular domains (G1, G2, G3), the horizontal line represents the protein core, and the vertical lines represent the sites of possible CS substitution.

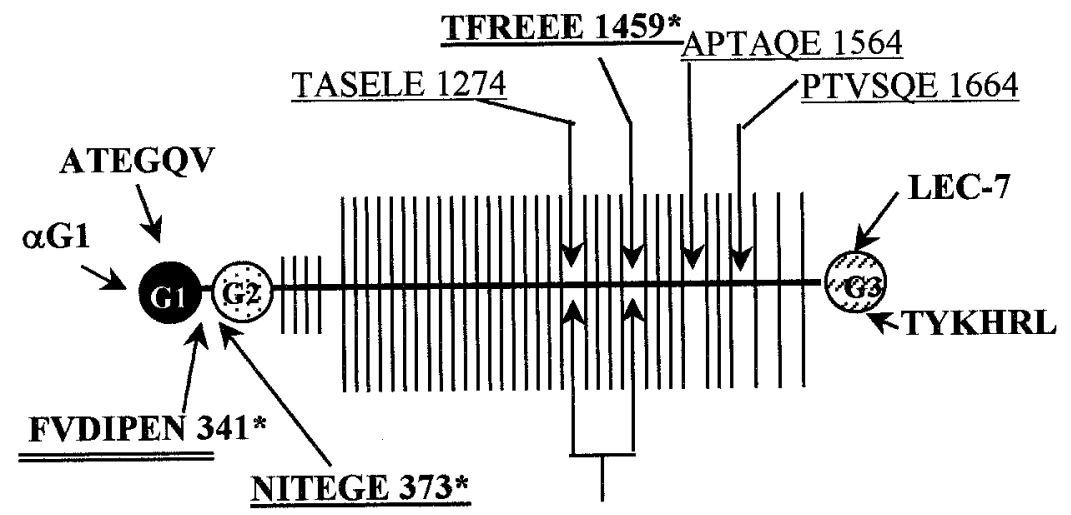

50kD KEEE-positive species
(G1, ATEGQV, TYKHRL, LEC-7, NITEGE, TFKEEE, and FVDIPEN) are shown in Figure 1 and described below. Three of these are neoepitope antisera (NITEGE, TFKEEE, and FVDIPEN). Anti-G1 was raised in rabbits by immunization with purified aggrecan G1 domain supplied by Dr. Larry Rosenberg (Montefiore Hospital). The production of ATEGQV, TYKHRL, and LEC-7 has been described previously (Sandy et al., 2000). Affinity-purified samples of NITEGE and FVDIPEN were kindly provided by Dr. John Mort at the Shriners Hospital in Montreal, Canada. TFKEEE was provided by Merck and Company (Rahway, NJ). It should be noted that the antisera that react with epitopes in the G1 domain (ATEGQV and G1) or the G3 domain (TYKHRL and LEC-7) of aggrecan react with full-length aggrecan and degradative products bearing the G1 or G3 domain alone, whereas the neoepitope antisera react only with specific degradation products. The immunizing peptides recognized by ATEGQV in the G1 domain (ATEGQVRVNSIYQDK VSLP) and by TYKHRL in the G3 domain (TYKHRLQRTMRPTRRSRPSMAH) are not present in the core protein of any other known proteoglycan. These two antibodies also were tested for reactivity with versican (VO and V1) from human smooth muscle cells (supplied by Dr. Richard Kenagy of Washington University, Seattle, WA), and it was shown (J. D. Sandy, C. Verscharen, and J. Westling, unpublished observations) that the versican core species detected with anti-versican V1 (from Dr. Richard LeBaron of University of Texas, San Antonio, TX) did not react with ATEGQV or TYKHRL. In the current set of experiments, we also show that these antibodies do not react with the brevican or neurocan core species (see Results). LEC-7 detects an aggrecan-specific peptide in the lectin motif of the aggrecan G3 domain (Sandy et al., 2000). TFKEEE detects the neoepitope generated by aggrecanase-dependent cleavage of the Glu ${ }^{1459}$ Gly ${ }^{1460}$ bond of rat aggrecan (Sandy et al., 1995). NITEGE detects the neoepitope generated by aggrecanase-dependent cleavage of the Glu ${ }^{373}$ Ala ${ }^{374}$ bond of rat aggrecan (Lark et al., 1995a,b,c; Sandy et al., 1995). FVDIPEN detects the neoepitope generated by MMP- or CatBdependent cleavage of the $\mathrm{Asn}^{341}-\mathrm{Phe}^{342}$ bond of rat aggrecan (Lark et al., 1995c; Mort et al., 1998). The specificity of the various aggrecan antisera was confirmed for CNS antigens in the present study by showing that controls without primary antibody did not detect the aggrecan species that are described.

The brevican monoclonal antiserum (RB18; generously provided by Dr. Yamaguchi, La Jolla, CA) was raised against the $80 \mathrm{kDa}$ C-terminal fragment of brevican and, therefore, detects both the full-length (145 $\mathrm{kDa}$ ) and the aggrecanase (ADAMTS)-generated C-terminal fragment $(80 \mathrm{kDa})$ (Yamada et al., 1995; Matthews et al., 2000).

The two different neurocan antisera used (1F6 and 1D1; Hybridoma Bank, Iowa City, IA) specifically recognize the $\mathrm{N}$-terminal and $\mathrm{C}$-terminal halves of the molecule, respectively, that are generated by proteolysis near the middle of the core protein (Meyer-Puttlitz et al., 1995; Olsson et al., 1996).

Quantification of aggrecan in spinal cord. The films produced from Western blots probed with anti-ATEG were scanned on a Hewlett Packard Desk Scan II and analyzed with Scion (NIH) Image Software using the Plot Profile function. Profiles (pixel density vs centimeters) were examined to determine the position of the discrete peaks for species A, C, E1, E2, and E3, and these were then measured as integrated pixel densities, with background subtraction, using the Measure function. Integrated pixel density data were then expressed as integrated pixel densities per milligram wet weight of tissue. Standard rat aggrecan (A1D1) was run on all gels and used to normalize data derived from different gels. A one-way ANOVA was used to determine whether the means differed between groups. Paired two-sample $t$ tests were run to specify the nature of those differences. A significance level of $p<0.05$ was set for all statistical analyses.

\section{RESULTS}

Our results show that immunoreactive aggrecan core protein species are present in the embryonic, postnatal, adult, and injured spinal cord. Three aggrecan-specific antibodies (ATEGQV, TYKHRL, and LEC-7) detected full-length aggrecan as well as many aggrecan degradative products in embryonic, postnatal, and adult spinal cord. Many of the aggrecan degradative products also were seen in injured spinal cord tissue at 1 and 2 weeks after injury. Aggrecan degradation fragments also were identified by specific neoepitope antisera (TFKEEE, NITEGE, and FVDIPEN). With the ATEGQV, G1, and LEC-7 antibodies, the full-length spinal cord rat aggrecan appeared smaller than the rat chondrosarcoma aggrecan on SDS-PAGE, presumably because of glycosylation differences. In addition to aggrecan, two other members of the aggrecan gene family were also identified. Brevican-specific antibodies (IF6 and 1D1) detected brevican in the adult spinal cord. RB18, a neurocan-specific antibody, detected neurocan in both the adult and PND1 spinal cord.

\section{ATEGQV and TYKHRL identify aggrecan and aggrecan degradative products in the spinal cord}

Aggrecan species that reacted with the ATEGQV antisera were abundant in embryonic, postnatal, and mature spinal cord extracts (Fig. 2, lanes 7-9, respectively). The banding pattern (A-E) was similar for the ATEGQV antisera in each sample. The mature sample also contained a series of species that reacted with the TYKHRL antisera (Fig. 2, lane 13). Both of these antibodies detected full-length aggrecan (band $\mathrm{A}$ at $\sim 350 \mathrm{kDa}$ ), and the identity of band A was confirmed by demonstrating that it also reacted strongly with anti-G1 (see Fig. 5, lane 5) and LEC-7 (see Fig. 5, lane 7). Many of the fragments appeared to correspond to known fragments in purified standard aggrecan from the Swarm RCS. Image overlay of the gels with molecular weight standard alignments showed that these antisera do not appear to detect the other aggregating proteoglycans present in these samples; thus, neurocan (Fig. 3, lanes 1, 2) and brevican (Fig. 3, lanes 3-6) were detected with core-specific antisera, and these proteins did not appear to react with either ATEGQV or TYKHRL.

The presence of both intact and fragmented aggrecan in spinal cord samples is similar to the situation in cartilage extracts and 


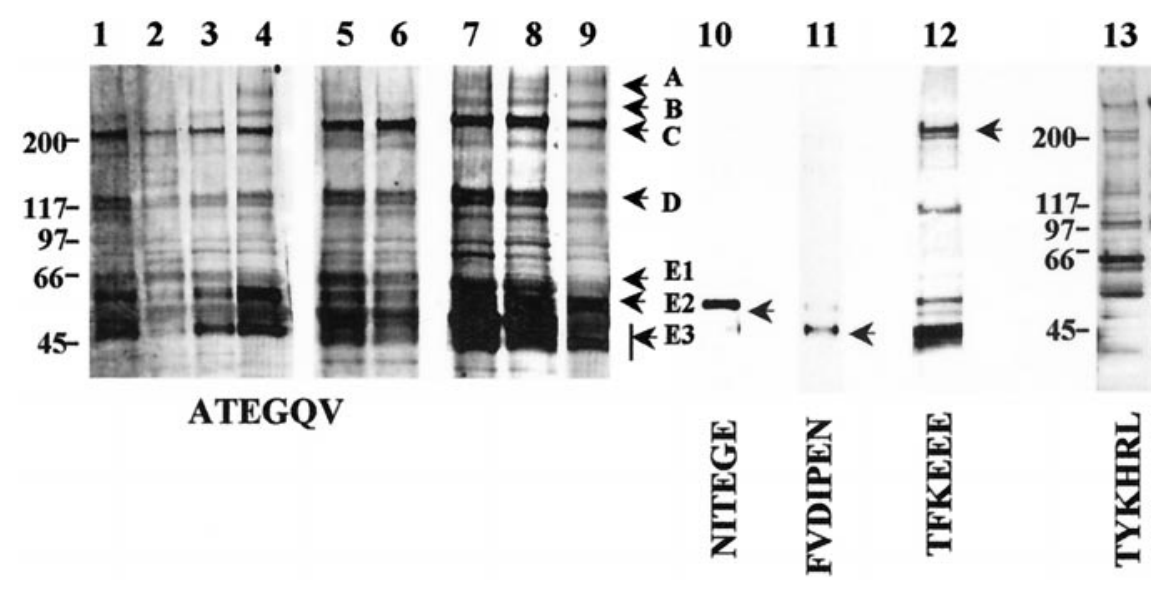

Figure 2. Western blot analysis of aggrecan in spinal cord tissue. Aggrecan is identified by a panel of antibodies. The ATEGQV antibody can identify fulllength aggrecan and aggrecan fragments. ATEGQV labeling is shown in injured-adult spinal cord tissue, harvested at 1 week after injury, rostral to the lesion epicenter (lane 1), at the lesion epicenter (lane 2), and caudal to the lesion epicenter (lane 3), in normal adult spinal cord (lane 4), in injured spinal cord tissue, harvested at 2 weeks after injury, rostral (lane 5) and caudal (lane 6) to the lesion epicenter, in E14 spinal cord (lane 7), in PND1 spinal cord (lane 8), and in normal adult spinal cord (lane 9). The $\sim 350 \mathrm{kDa}$ band is referred to as band $A$, the $\sim 250 \mathrm{kDa}$ band is $B$, the $\sim 220 \mathrm{kDa}$ band is $C$, the $\sim 135 \mathrm{kDa}$ band is $D$, the $\sim 60$ $\mathrm{kDa}$ band is $E 1$, the $\sim 55 \mathrm{kDa}$ band is $E 2$, and the $\sim 52$ and $\sim 50 \mathrm{kDa}$ bands collectively are E3. Some of the aggrecan (ATEGQV-positive) degradative fragments are identified by neoepitope antisera in normal adult spinal cord tissue. These include the following: NITEGE-positive $60 \mathrm{kDa}$ band (lane 10; which also is the E2 band identified with ATEGQV), FVDIPEN-positive $\sim 52 \mathrm{kDa}$ band (lane 11; which also is the E3 band identified with ATEGQV), and TFKEEE-positive $220 \mathrm{kDa}$ band (and other smaller fragments; lane 12). The TYKHRL antibody can identify full-length aggrecan and aggrecan fragments. TYKHRL labeling is shown in normal adult spinal cord tissue (lane 13). Molecular weights in kilodaltons are shown on the left of lanes 1 and 13.

1

2

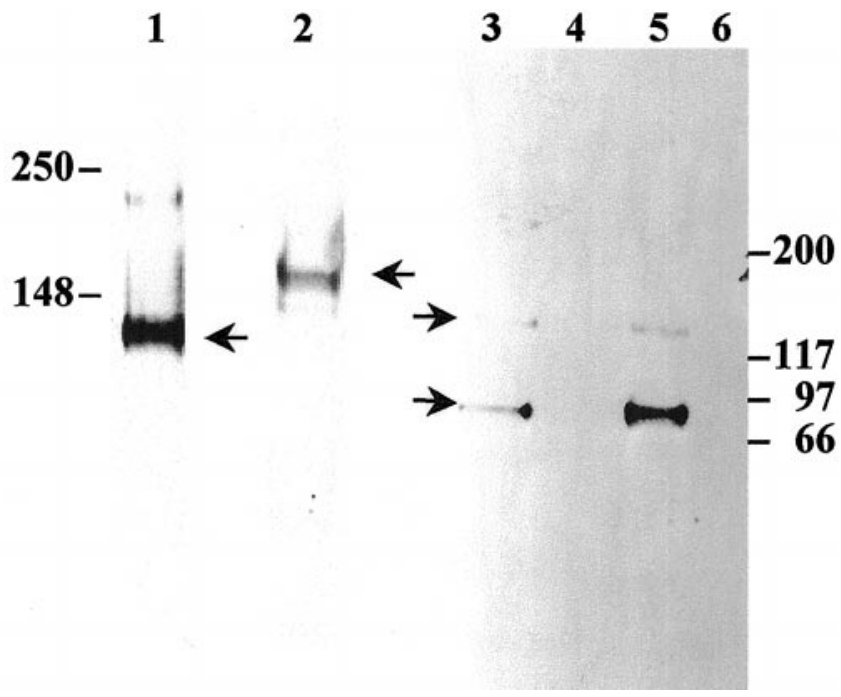

Figure 3. Western blot analysis of neurocan and brevican in spinal cord tissue. 1F6 (lane 1) and 1D1 (lane 2) antisera label 130 and $150 \mathrm{kDa}$ neurocan-positive bands, respectively, in normal adult spinal cord. RB18 labels both a 145 and an $80 \mathrm{kDa}$ brevican-positive band in normal adult spinal cord (lane 3) and PND1 spinal cord (lane 5). RB18 did not detect brevican in E14 spinal cord (lane 4) or RCS (lane 6). Immature tissues were not probed for neurocan (IF6 and 1D1).

cultured chondrocytes stimulated with cytokines in which multiple C-terminally truncated forms are present. The fragments in cartilage, thus far, have been shown to be the result of aggrecan degradation by aggrecanases (ADAMTS), MMPs, and possibly CatB (Sandy et al., 1991, 1992, 1995, 1998; Fosang et al., 1992; Hughes et al., 1995; Grumet et al., 1996; Rauch et al., 1997; Mort et al., 1998; Sandy and Lark, 1999). In this regard, there are several reasons why it is likely that the aggrecan patterns seen with spinal cord samples are valid descriptions of the molecule as it exists in vivo and not a result of proteolysis during preparation. First, some of the fragments are identical to well characterized fragments present in cartilage extracts. Second, the same spinal cord samples contained high molecular forms of both brevican and neurocan (see Results) that are identical to those described previously by others in brain extracts (Meyer-Puttlitz et al., 1995; Yamada et al., 1995; Olsson et al., 1996; Matthews et al., 2000).
To simplify description of the ATEGQV-positive bands (Fig. 2, lanes 1-9), we refer to the bands as follows: the $\sim 350 \mathrm{kDa}$ band (full-length aggrecan core protein, which also reacted with G1, TYKHRL, and LEC-7) as A, the $\sim 250 \mathrm{kDa}$ band as $\mathrm{B}, \sim 220$ $\mathrm{kDa}$ band as $\mathrm{C}, \sim 135 \mathrm{kDa}$ band as $\mathrm{D}$, the $\sim 60 \mathrm{kDa}$ band as E1, the $\sim 55 \mathrm{kDa}$ band as $\mathrm{E} 2$, and the $\sim 52$ and $\sim 50 \mathrm{kDa}$ bands collectively as E3. The robust staining of bands $\mathrm{C}-\mathrm{E}$ suggest that these species are the most abundant in spinal cord.

\section{Some aggrecan degradation products are identified by neoepitope antisera}

Aggrecan neoepitope antisera (TFKEEE, NITEGE, and FVDIPEN) were used to identify a number of the ATEGQVpositive bands present in normal adult spinal cord. First, the TFKEEE antiserum detected a product at $\sim 220 \mathrm{kDa}$ that comigrated with band $\mathrm{C}$ (Fig. 2, lane 12) and that has properties consistent with the species G1-TFREEE ${ }^{1459}$ (see Fig. 4). This species is generated by ADAMTS-4 cleavage of aggrecan in solution (Tortorella et al., 2000) and is seen in both rat chondrosarcoma and human cartilage extracts (Sandy et al., 1998, 2000, 2001). The other major TFKEEE-positive band migrated at $\sim 50$ $\mathrm{kDa}$, consistent with its identification as the ADAMTS-generated product $\mathrm{Gly}^{1275}$-Glu ${ }^{1459}$ (see Fig. 1 for explanation) that has been identified as the product of ADAMTS-4 cleavage at Glu ${ }^{1274}$ and $\mathrm{Glu}^{1459}$ in solution (Tortorella et al., 2000). Interestingly, this aggrecan product and other $\mathrm{C}$-terminal fragments of this kind have not been detected in cartilage extracts presumably because they are lost rapidly by diff usion into the synovial fluid. Second, the NITEGE antiserum detected a single $\sim 60 \mathrm{kDa}$ species (Fig. 2, lane 10) that comigrated with the ATEGQV-positive species E2 (Fig. 2). This species (see Fig. 4) results from ADAMTS-4 cleavage at the $\mathrm{Glu}^{373}-\mathrm{Ala}^{374}$ bond of aggrecan (Tortorella et al., 2000 ), and it is also a major aggrecan product that is present in extracts of rat and human cartilages (Sandy et al., 2000, 2001). Third, the FVDIPEN antiserum detected an $\sim 52 \mathrm{kDa}$ species (Fig. 2, lane 11) that comigrated with one component of the ATEGQV-positive band E3 (Fig. 2, lanes 1-9). There was also some minor cross-reactivity with band E2 that has been seen previously with human cartilage G1 species on Western blot analysis (Sandy et al., 1995). The G1-FVIDPEN ${ }^{341}$ species is a product of MMP or CatB digestion of aggrecan (Mort et al., 


\section{Aggrecan species in rat spinal cord}
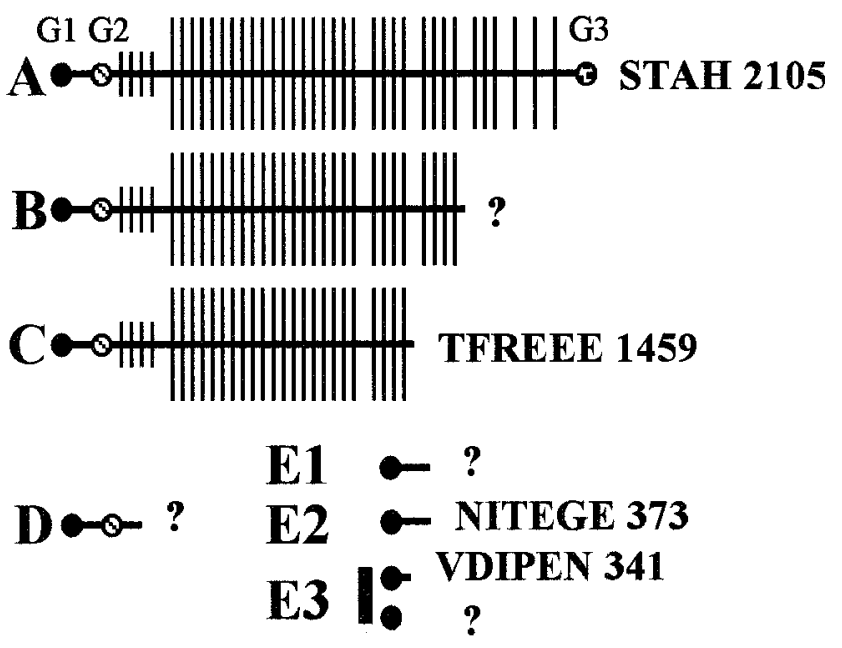

Figure 4. Schematic of structures for aggrecan species found in rat spinal cord and corresponding to bands $A-E 3$ in Figure 2. The aggrecan core proteins are represented as horizontal lines, and the globular domains on the core are represented as circles. The long vertical lines represent the CS chains, and the short vertical lines represent KS chains. The glycosylation abundance is unknown for aggrecan in the spinal cord but is shown here as it is thought to occur in adult cartilage. C-terminal sequences are shown where they have been determined. Question marks denote unknown $\mathrm{C}$ terminals.

1998), and it is also a major aggrecan product that is present in rat and human cartilage (Flannery et al., 1992).

The identity of the ATEGQV-positive doublet band D protein (Fig. 2, lanes 1-9) is unknown at present; however, the migration behavior of the doublet is consistent with a "double-globe" species consisting of the G1 and globular domain 2 (G2) domains only, generated by cleavage on the $\mathrm{C}$-terminal side of the $\mathrm{G} 2$ domain (see Fig. 4); this type of product is also abundant in rat and human cartilage extracts (Sandy et al., 2000, 2001). The identity of the band E3 species of lowest molecular weight that does not react with the anti-VDIPEN is unknown at present but presumably represents more truncated forms of the aggrecan G1 domain. The structures of the spinal cord aggrecan species termed A-E3 are represented pictorially in Figure 4 where established $\mathrm{C}$ terminals are given and unknown $\mathrm{C}$ terminals are described with a question mark. The structures of the TYKHRLpositive (Fig. 2, lane 13) and LEC-7-positive (data not shown) bands have not been as extensively studied as the G1 products although band $\mathrm{A}$ is clearly indicated. The apparently abundant TYKHRL-positive doublet at $\sim 60 \mathrm{kDa}$ shows a migration behavior that is consistent with a product formed by the release of the G3 domain from full-length aggrecan by cleavage at a site that is within the sparsely GAG-substituted region adjacent to the G3 domain. As would be expected for a freely diffusible product, this G3 species has not been detected in cartilage extracts (Sandy and Verscharen, 2001).

\section{Migration patterns differ between spinal cord and cartilage aggrecan}

Full-length aggrecan (G1-G3) in spinal cord migrated faster than did the full-length RCS aggrecan. This was consistently seen with all four antisera (ATEGQV, TYKHRL, G1, and LEC-7) that are capable of identifying full-length aggrecan (Fig. 5, lanes 1, 2, $5-8$ ). This faster migration pattern also was seen with the high-

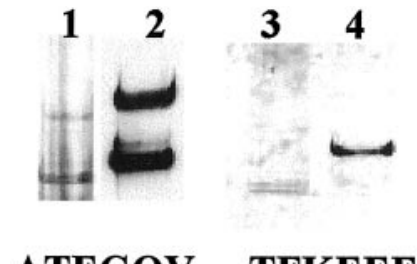

ATEGQV TFKEEE

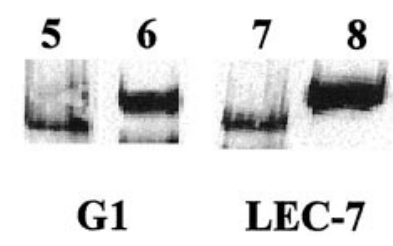

Figure 5. Migration differences in spinal cord and cartilage aggrecan. ATEGQV labeling of full-length aggrecan core protein (Fig. 2, band $A$ ) and the $\sim 250 \mathrm{kDa}$ species (Fig. 2, band $B$ ) in normal adult spinal cord (lane 1) and RCS (lane 2) is shown. TFKEEE neoepitope labeling of a large aggrecan fragment (Fig. 2, band $C$ ) in normal adult spinal cord (lane 3 ) and RCS (lane 4) is shown. G1 labeling of full-length aggrecan core protein in the normal adult spinal cord (lane 5) and RCS (lane 6) is shown. LEC-7 labeling of full-length aggrecan core protein in the normal adult spinal cord (lane 7) and RCS (lane 8) is shown. Although lanes may not have been adjacent, migration patterns were compared only in lanes run on the same gel.

molecular weight TFKEEE-reactive band C (Fig. 5, lanes 3, 4). Band $\mathrm{C}$ is a large aggrecan product that contains the $\mathrm{G} 1$ and $\mathrm{G} 2$ domains as well as a large portion of the CS attachment region (Figs. 1, 4). Because both the chondrosarcoma and spinal cord samples contain full-length aggrecan core protein, the faster migration of the spinal cord species is probably a result of a lower degree of substitution with O-linked oligosaccharides and/or CS linkage regions, both of which are not removed by chondroitinase. The differences in migration patterns are consistent with what has been shown in a nonmammalian system and attributable to glycosylation differences. Specifically, brain-derived aggrecan in the developing chicken is substituted with less CS and contains no keratan sulfate in contrast to cartilage ( $\mathrm{Li}$ et al., 1996). Thus, although the CS content of cartilage aggrecan is generally $\sim 90 \%$ of the total molecular weight, the CS content of the spinal cord molecule may be much lower, perhaps reflecting a different requirement for $\mathrm{CS}$ in the function of the molecule in the two tissues.

\section{Effects of spinal cord injury on aggrecan}

Many aggrecan fragments also were detected in the injured spinal cord using ATEGQV and TYKHRL antibodies. The staining patterns appeared similar at the level of the lesion as well as rostral and caudal to the injury site (Fig. 2, lanes 1-3, 5, 6). In many aspects, these bands were very similar to those seen in normal embryonic, postnatal, and adult spinal cord tissues. To provide information on the effect of injury on the tissue content of aggrecan core protein species, we determined the content of species A, C, E1, E2, and E3 by densitometric analysis of these bands on anti-ATEG Western blots of five normal rats, five rats at 1 week after injury, and five rats at 2 weeks after injury. A set of typical Western blots and plot profiles for these three groups of animals is shown in Figure 6. Content data (i.p.d./mg wet weight) shown as the mean $( \pm \mathrm{SD})$ for total immunoreactive aggrecan (species $\mathrm{A}+\mathrm{C}+\mathrm{E} 1+\mathrm{E} 2+\mathrm{E} 3)$ and for each species are given in Figure 7. The data show that SCI is accompanied by marked quantitative changes in the total immunoreactive aggrecan and in 


\section{Representative Changes in Individual Aggrecan Core Species}

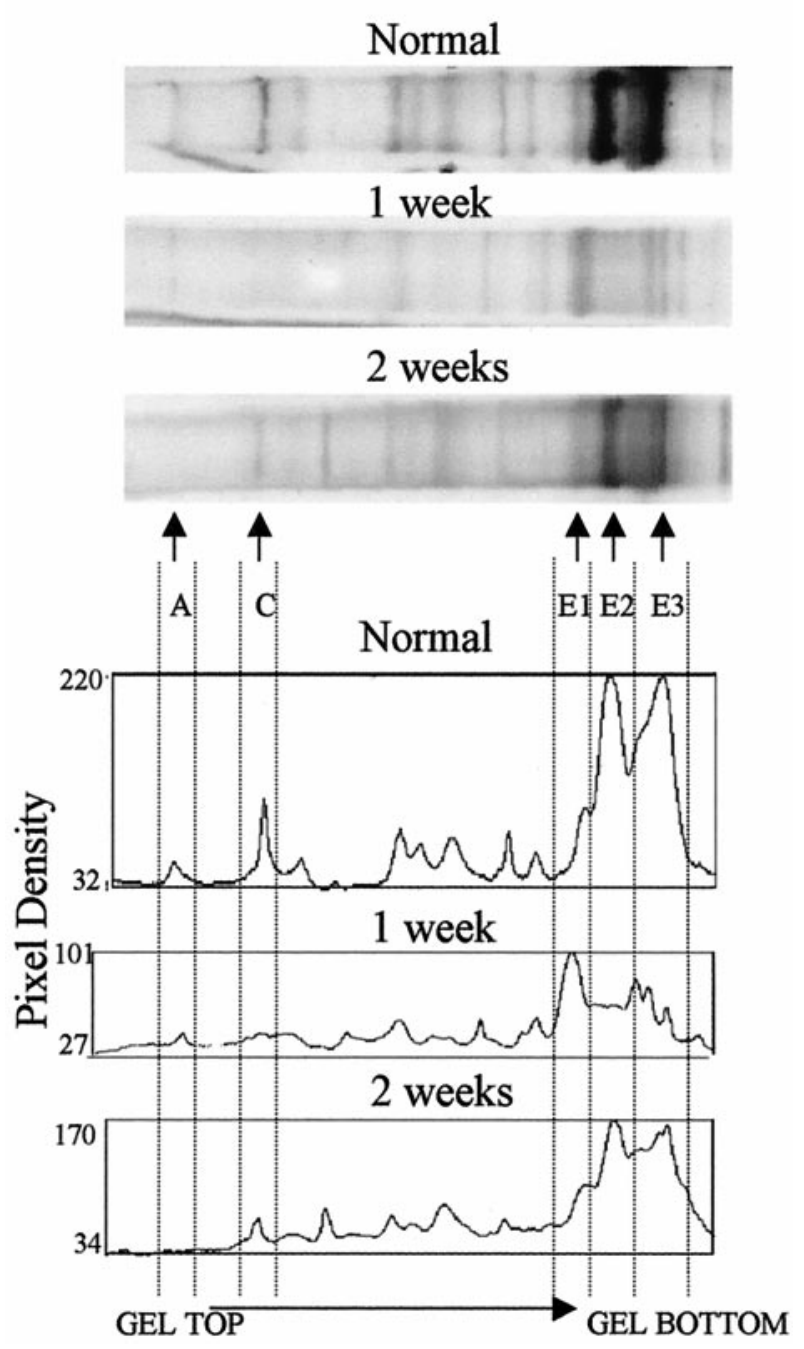

Figure 6. Representative changes in individual aggrecan core species. ATEGQV Western blot of aggrecan core proteins in representative samples of spinal cord from normal animals and animals 1 and 2 weeks after injury. For each lane, plot profiles were obtained to facilitate identification and quantitation of the specific aggrecan core protein products $(A, C, E 1, E 2, E 3)$ by determination of integrated pixel density with background subtraction.

individual aggrecan species. First, the total aggrecan content (mean, 10.7) in normal animals is reduced by $65 \%$ to a mean of 3.8 at 1 week after injury, and this recovers to a mean of 6.0 that is $56 \%$ of the normal content by 2 weeks (Fig. $7 A$ ). A single-factor ANOVA, with an $\alpha$ level of 0.05 , shows that there is a significant difference between the aggrecan content in the normal and injured tissues $\left(F_{(2,12)}=18.11 ; p<0.001\right)$. Paired two-sample $t$ tests show that there is a significant reduction in aggrecan content from normal values at both 1 week $[t(4)=4.164 ; p=0.014]$ and 2 weeks $[t(4)=4.28 ; p=0.013]$ after injury. The differences in (recovery of) aggrecan content between 1 and 2 weeks after injury are marginally significant $[t(4)=-2.7 ; p=0.053]$. These results presumably reflect an initial period of matrix degradation followed by an attempted repair that is not yet complete at 2 weeks. The proteases involved in this period of spinal aggrecan

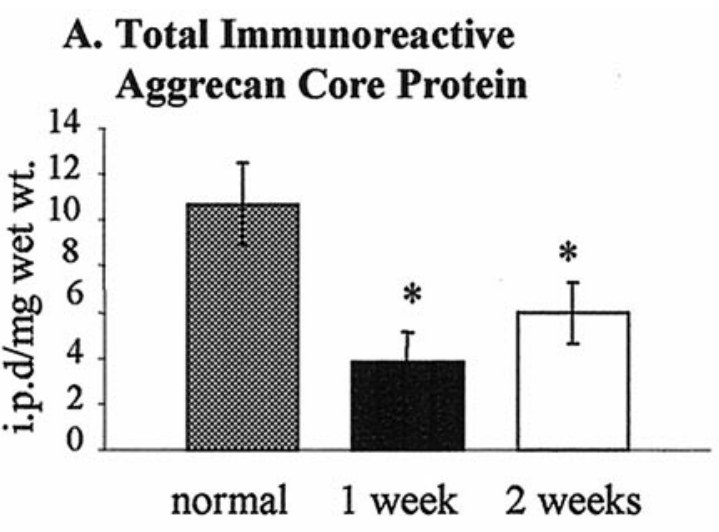

\section{B. Mean Content of Individual Aggrecan Core Species}

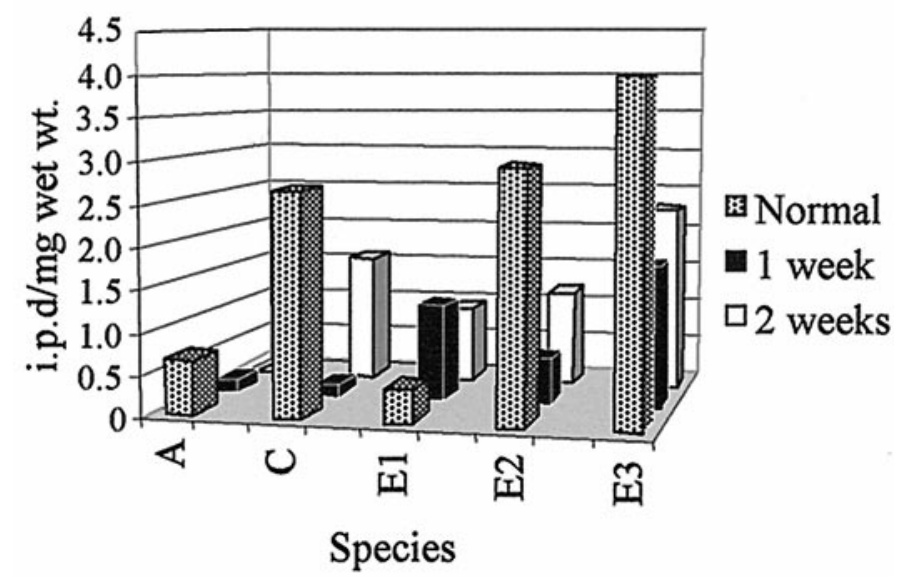

Figure 7. Determination of total aggrecan core protein content. $A$, Total immunoreactive aggrecan core protein decreased markedly after SCI. An asterisk indicates statistically significant changes from normal. The increase in core protein content from 1 to 2 weeks after injury was marginally significant but is not indicated on the graph (see text for statistical details). $B$, Mean content of individual aggrecan core species is shown. Comparisons of readily identified and quantified aggrecan species (see Fig. 6) show that the quantity of the different aggrecan species varies markedly and reproducibly with time after injury (see text for details). SDs are not shown in $B$ but are as follows: normal, $A(0.21), C(0.33), E 1$ (0.13), E2 (0.52), and $E 3$ (0.94); 1 week after injury, $A(0.15), C(0.17), E 1$ (0.78), $E 2$ (0.43), and $E 3$ (0.74); and 2 weeks after injury, $A(0), C(0.67)$, $E 1$ (0.72), E2 (0.78), and E3 (0.79). i.p.d, Integrated pixel density; wt., weight.

remodeling are indicated by the species-specific changes that occur over this period (Fig. $7 B)$. The full-length $(\sim 350 \mathrm{kDa})$ aggrecan core protein (band $\mathrm{A}$ ) represents $<4 \%$ of the total aggrecan content in normals and appears to be lost after injury. Because of its small representation, the functional implications of the loss of band $\mathrm{A}$ are unclear. In contrast, the loss of band $\mathrm{C}$ at 1 week and its recovery at 2 weeks after injury would probably accompany significant functional changes in the CS content because it represents the major putative CS-bearing aggrecan species in the tissue. Initially this loss of band $\mathrm{C}$ material correlates with an increase in band E1. The precise $\mathrm{C}$ terminal of E1 is unknown; however, its migration pattern is consistent with the species G1-ILTVKP384, a likely minor product of aggrecan cleavage by MMP-13 (Fosang et al., 1996). Interestingly, the data 
show that the terminal product of aggrecan degradation by ADAMTS activity (G1-NITEGE-373), species E2, is a major component of the normal aggrecan matrix and is markedly reduced after injury. Loss of this component would not require proteolysis (like the larger glycosylated species) and may be caused by endocytosis or loss into the CSF. The increase of species E3, a major component of which is G1-VIPEN341, suggests that injury is accompanied by increased MMP-like activity in the aggrecancontaining region(s) of the tissue.

\section{Other aggregating proteoglycans are present in the spinal cord}

Brevican and neurocan also were detected in normal spinal cord. A specific brevican antibody (RB18) identified two bands (145 and $80 \mathrm{kDa}$ ) in the adult and PND1 spinal cord (Fig. 3, lanes 3, 5); however, brevican was not detected in E14 spinal cord (Fig. 3, lane 4) or RCS aggrecan samples (Fig. 3, lane 6). Neurocan was identified in the adult spinal cord with two antibodies (1F6 and 1D1) generated against epitopes in the $\mathrm{N}$ - and C-terminal halves of the molecule (Rauch et al., 1992; Meyer-Puttlitz et al., 1995) (Fig. 3, lanes 1, 2). The 1F6 antibody labeled an $\sim 130 \mathrm{kDa}$ band in adult spinal cord tissue, and the 1D1 antibody labeled an $\sim 150$ $\mathrm{kDa}$ band. Both of these products appear to correspond to neurocan products identified previously as specific proteolytic fragments of neurocan in the brain (Rauch et al., 1991, 1992; Engel et al., 1996; Meyer-Puttlitz et al., 1996; Katoh et al., 1998).

\section{DISCUSSION}

These studies show that aggrecan is present in the embryonic, neonatal, adult, and injured-adult rat spinal cord. The results are in agreement with other studies that have shown that aggrecan is present in the developing and adult mammalian brain (Salmivirta et al., 1996; Milev et al., 1998b) as well as the developing avian brain (Li et al., 1996; Schwartz et al., 1996, 1999). In addition, these results are consistent with previous studies that describe an "aggrecan-like" protein in the adult dog, rat, and hamster spinal cord (Zaremba et al., 1989; Kalb and Hockfield, 1990; Fryer et al., 1992; Asher et al., 1995). Our studies extend the previous work in three ways: (1) the use of two well characterized aggrecan-specific antibodies (ATEGQV and TYKHRL) to identify and quantify full-length aggrecan and many aggrecan-specific degradative products on Western blots, (2) identification of aggrecan (fulllength core protein and many degradative products) in embryonic, postnatal, adult, and injured spinal cord, and (3) the use of neoepitope antibodies (NITEGE, FVDIPEN, and TFKEEE) that identify aggrecan-specific degradative fragments.

\section{The presence of aggrecan in the developing and mature CNS}

Full-length aggrecan core protein $(\sim 350 \mathrm{kDa})$ and several degradative aggrecan products were detected and characterized with ATEGQV and TYKRHL antibodies in embryonic, neonatal, and adult rat spinal cord. The pattern of aggrecan bands did not appear to differ markedly between E14, PND1, and adult spinal cord. These results suggest that aggrecan has the same range of core protein species independent of age and that the majority of aggrecan in spinal cord at all ages is in C-terminally truncated forms. In this regard, we cannot entirely exclude the possibility that some of the fragmentation occurred during preparation. However, this would have to be aggrecan specific because both neurocan and brevican were essentially intact in the same samples prepared for Western blot analysis. If, as seems likely, the aggrecan is primarily fragmented in the spinal cord in vivo, this would be very similar to aggrecan in the intervertebral disk (Sztrolovics et al., 1997) and in mature articular cartilages (Lark et al., 1995a,b,c). This makes aggrecan somewhat different from other proteoglycans, such as brevican (Yamaguchi, 1996) and neurocan (Rauch et al., 1991), both of which undergo specific, but limited, age-dependent degradative processing in vivo in the CNS. It is of course likely that marked variations exist in the CS glycosylation patterns on aggrecan at different ages and after injury in the spinal cord as has been well documented for cartilage aggrecan (Plaas et al., 1998). Although the role of aggrecan in the normal CNS is unclear, it is likely that it is a function of both the core protein and GAG substituents. For example, the influence of aggrecan in spinal cord growth and repair is consistent with the documented effects of CSPGs as a group, and aggrecan could represent or contribute to the CSPGs that repel migrating cells and act as a guidance molecule during development (Steindler et al., 1990; Oakley and Tosney, 1991; Oakley et al., 1994; Wilson and Snow, 2000). Aggrecan and other CSPGs also inhibit neurite growth in cell culture (Snow et al., 1990, 1996; Snow and Letourneau, 1992; Wilson and Snow, 2000), and their abundance appears to be correlated with a lack of regeneration after SCI (Fitch and Silver, 1997; Lemons et al., 1999). In addition, aggrecan, like other proteoglycans, may influence the matrix of the spinal cord by binding hyaluronan through the G1 domain and specific molecules such as tenascin through the G3 domain (Rauch et al., 1997; Milev et al., 1998a,b). The role of CSPGs in binding other matrix molecules is well illustrated by the binding of TGF- $\beta$ by decorin (Boyd et al., 1990; Andres et al., 1992; Hildebrand et al., 1994). In cartilage and maybe to some extent in the CNS, the osmotic effect of the high density of negative charge on aggrecan allows it to bind water, and this in combination with a restraining network, such as collagen fibrils, allows it to contribute to the turgor and integrity of this tissue. Although the effects of specific GAG components in the CNS are not yet clear, some studies suggest that CS GAG chains alone, irrespective of the protein core of the PG, can inhibit neurite outgrowth (Snow et al., 1990, 1991; Snow and Letourneau, 1992). In addition, the spatial and temporal expression patterns of CS GAG chains have been correlated with a lack of regrowth after SCI (Fitch and Silver, 1997; Lemons et al., 1999). Thus, it is reasonable to hypothesize that both the subdomains of the aggrecan core protein and its GAG constituents have discrete functional roles in spinal cord physiology.

\section{Specific aggrecan degradative products are present in the spinal cord}

The ADAMTS family of proteases appears to be responsible for the cleavage of several different aggregating proteoglycans in a variety of tissues including cartilage (Arner et al., 1999; Tortorella et al., 1999), brain (Yamada et al., 1995), and aorta (Sandy et al., 2001). This is the first time, to our knowledge, that aggrecan products generated by the ADAMTS family of proteases have been shown to occur in the CNS. Thus, although these results are the first to support the presence and activity of aggrecanase or an aggrecanase-like enzyme in the spinal cord, this maybe is not surprising because ADAMTS-4 (aggrecanase-1) was first cloned from a human brain library (Kuno et al., 1997).

A $52 \mathrm{kDa}$ aggrecan fragment that reacted with both ATEGQV and FVDIPEN antisera was seen in spinal cord tissue. This fragment (G1-VDIPEN341) that also is present in cartilage can be generated by MMP or Cat B treatment of aggrecan (Lark et al., 1995c; Mort et al., 1998). Because a variety of metalloprotein- 
ases have been identified in the spinal cord (Chandler et al., 1997; Kieseier et al., 1998; Pagenstecher et al., 1998), it is perhaps not surprising that the FVDIPEN fragment is present. It, therefore, appears that spinal cord aggrecan is susceptible to many of the same degradative processes that occur in articular cartilage and intervertebral disk.

\section{The quantity of individual aggrecan core protein species is markedly altered by $\mathrm{SCl}$}

Although overall aggrecan core protein content is significantly reduced after SCI (Fig. 7), many of the ATEGQV- and TYKHRL-positive bands detected in normal spinal cord tissue were present at 1 and 2 weeks after injury (Figs. 2, lanes 1-3, 5, 6, 6) This suggests that the enzymes that cleave aggrecan in the spinal cord at 1 and 2 weeks after injury are similar to those present in the uninjured spinal cord or that novel aggrecan fragments generated after injury are rapidly cleared from the tissue.

Interestingly, full-length aggrecan core protein $(\sim 350 \mathrm{kDa})$ was consistently undetectable at 1 week after injury, suggesting (1) that the injury inhibits production of aggrecan and the small amount of full-length core protein is cleared by normal turnover and/or (2) that injury activates proteolysis of full-length aggrecan. Indeed, it is not uncommon for proteins to be degraded after SCI because of increased production of enzymes. For example, expression of MMP-2 and -9 increases after injury in vivo and is produced by activated microglia and astrocytes in vitro (Gottschall et al., 1995; Rosenberg, 1995; Pagenstecher et al., 1998; Romanic et al., 1998). Thus, increases in enzymes, such as MMPs, may contribute to an extended postinjury degradation of aggrecan.

It is possible that some of the putative CS-substituted aggrecan fragments that are normally present (bands B-D) may be capable of inhibiting neurite growth (Pettway et al., 1990; Brittis et al., 1992; Risling et al., 1993); however, we have not determined the extent of CS substitution on any of the aggrecan species described. In this regard, it appears as if some proteoglycans, such as NG2, can inhibit growth via their protein core (Dou and Levine, 1994), and it is, therefore, possible that a particular fragment of aggrecan core protein alone is capable of inhibiting neurite growth.

Overall, our data present a framework for the matrix events that follow SCI and repair. The identification of specific aggrecan species provides, for the first time, information on the proteases involved and the nature of the remodeling process. To what extent these changes can provide an explanation for the marked alteration in CS immunoreactivity in SCI models will require analysis of the GAG content (constituents) of the specific proteoglycans.

\section{Other aggregating proteoglycans are present in the spinal cord}

Our results in the developing and adult spinal cord confirm and extend previous findings on brevican and neurocan in the CNS. There is no previous documentation showing brevican in the spinal cord, although it has been shown in the brain (Yamaguchi, 1996; Yamada et al., 1997; Milev et al., 1998b; Seidenbecher et al., 1998). The abundance of RB18-positive fragments (80 and 145 $\mathrm{kDa}$ ) in postnatal and mature spinal cord and their apparent absence from E14 spinal cord (Fig. 3, lanes 3-6) support the finding that brevican accumulates with age in the CNS (Milev et al., 1998b).
The 1D1 and 1F6 neurocan antibodies identified neurocan in the adult spinal cord. Previously, neurocan has been shown only in the adult and embryonic brain and in the embryonic spinal cord (Engel et al., 1996; Meyer-Puttlitz et al., 1996; Katoh et al., 1998). Full-length neurocan core protein $(\sim 245 \mathrm{kDa})$, however, was not seen here in the adult spinal cord with either of these antibodies, in agreement with other studies showing that the $245 \mathrm{kDa}$ protein is not present in significant amounts in the adult brain (Rauch et al., 1991). The lower molecular weight 1D1- and 1F6-positive bands (150 and $130 \mathrm{kDa}$, respectively) that we identified in adult spinal cord are, therefore, similar to the neurocan species seen previously in the adult brain (Rauch et al., 1991, 1992).

In conclusion, we have unambiguously identified aggrecan in the embryonic, adult, and injured rat spinal cord. Aggrecan and its fragments may well represent part of the CSPG population that can inhibit growth (Snow and Letourneau, 1992; Snow et al., 1996), serve as a developmental guidance molecule for both cell and axonal migration (Pettway et al., 1990, 1996; Fichard et al., 1991; Oakley and Tosney, 1991; Perris et al., 1991; Oakley et al., 1994; Landolt et al., 1995), or possibly contribute to the lack of regeneration after CNS injury (Gates et al., 1996; Davies et al., 1997; Lemons et al., 1999).

\section{REFERENCES}

Andres JL, DeFalcis D, Noda M, Massague J (1992) Binding of two growth factor families to separate domains of the proteoglycan betaglycan. J Biol Chem 267:5927-5930.

Arner EC, Pratta MA, Trzaskos JM, Decicco CP, Tortorella MD (1999) Generation and characterization of aggrecanase. J Biol Chem 274:6594-6601.

Asher RA, Scheibe RJ, Keiser HD, Bignami A (1995) On the existence of a cartilage-like proteoglycan and link proteins in the central nervous system. Glia 13:294-308.

Boyd FT, Cheifetz S, Andres J, Laiho M, Massague J (1990) Transforming growth factor-beta receptors and binding proteoglycans. J Cell Sci Suppl 13:131-138.

Brittis PA, Canning DR, Silver J (1992) Chondroitin sulfate as a regulator of neuronal patterning in the retina. Science 255:733-736.

Chandler S, Miller KM, Clements JM, Lury J, Corkill D, Anthony DC, Adams SE, Gearing AJ (1997) Matrix metalloproteinases, tumor necrosis factor and multiple sclerosis: an overview. J Neuroimmunol 72:155-161.

Davies SJ, Fitch MT, Memberg SP, Hall AK, Raisman G, Silver J (1997) Regeneration of adult axons in white matter tracts of the central nervous system. Nature 390:680-683.

Doege K, Sasaki M, Horigan E, Hassell JR, Yamada Y (1987) Complete primary structure of the rat cartilage proteoglycan core protein deduced from cDNA clones. J Biol Chem [Erratum (1988) 263:10040] 262:17757-17767.

Doege KJ, Sasaki M, Kimura T, Yamada Y (1991) Complete coding sequence and deduced primary structure of the human cartilage large aggregating proteoglycan, aggrecan. J Biol Chem 266:894-902.

Dou CL, Levine JM (1994) Inhibition of neurite growth by the NG2 chondroitin sulfate proteoglycan. J Neurosci 14:7616-7628.

Engel M, Maurel P, Margolis RU, Margolis RK (1996) Chondroitin sulfate proteoglycans in the developing central nervous system. I. Cellular sites of synthesis of neurocan and phosphacan. J Comp Neurol 366:34-43.

Fichard A, Verna JM, Olivares J, Saxod R (1991) Involvement of a chondroitin sulfate proteoglycan in the avoidance of chick epidermis by dorsal root ganglia fibers: a study using beta-D-xyloside. Dev Biol 148:1-9.

Fitch MT, Silver J (1997) Activated macrophages and the blood-brain barrier: inflammation after CNS injury leads to increases in putative inhibitory molecules. Exp Neurol 148:587-603.

Flannery CR, Lark MW, Sandy JD (1992) Identification of a stromelysin cleavage site within the interglobular domain of human aggrecan. Evidence for proteolysis at this site in vivo in human articular cartilage. J Biol Chem 267:1008-1014.

Fosang AJ, Neame PJ, Last K, Hardingham TE, Murphy G, Hamilton JA (1992) The interglobular domain of cartilage aggrecan is cleaved by PUMP, gelatinases, and cathepsin B. J Biol Chem 267:19470-19474.

Fosang AJ, Last K, Knauper V, Murphy G, Neame PJ (1996) Degradation of cartilage aggrecan by collagenase-3 (MMP-13). FEBS Lett 380:17-20.

Fryer HJL, Kelly GM, Molinaro L, Hockfield S (1992) The high molec- 
ular weight Cat-301 chondroitin sulfate proteoglycan from brain is related to the large aggregating proteoglycan from cartilage, aggrecan. J Biol Chem 267:9874-9883.

Gates MA, Fillmore H, Steindler DA (1996) Chondroitin sulfate proteoglycan and tenascin in the wounded adult mouse neostriatum in vitro: dopamine neuron attachment and process outgrowth. J Neurosci 16:8005-8018.

Gottschall PE, Yu X, Bing B (1995) Increased production of gelatinase B (matrix metalloproteinase-9) and interleukin-6 by activated rat microglia in culture. J Neurosci Res 42:335-342.

Grumet M, Friedlander DR, Sakurai T (1996) Functions of brain chondroitin sulfate proteoglycans during developments: interactions with adhesion molecules. Perspect Dev Neurobiol 3:319-330.

Hascall VC, Calabro A, Midura RJ, Yanagishita M (1994) Isolation and characterization of proteoglycans. Methods Enzymol 230:390-417.

Hildebrand A, Romaris M, Rasmussen LM, Heinegard D, Twardzik DR, Border WA, Ruoslahti E (1994) Interaction of the small interstitial proteoglycans biglycan, decorin and fibromodulin with transforming growth factor beta. Biochem J 302:527-534.

Hughes CE, Caterson B, Fosang AJ, Roughley PJ, Mort JS (1995) Monoclonal antibodies that specifically recognize neopeptide sequences generated by "aggrecanase" and matrix metalloproteinase cleavage of aggrecan; application to catabolism in situ and in vitro. Biochem J 305:799-804

Kalb RG, Hockfield S (1990) Large diameter primary afferent input is required for expression of the CAT-301 proteoglycan on the surface of motor neurons. Neuroscience 34:391-401.

Katoh SR, Matsuda M, Watanabe E, Maeda N, Oohira A (1998) Two types of brain chondroitin sulfate proteoglycan: their distribution and possible functions in the rat embryo. Neurosci Res 31:273-282.

Kieseier BC, Kiefer R, Clements JM, Miller K, Wells GM, Schweitzer T, Gearing AJ, Hartung HP (1998) Matrix metalloproteinase-9 and -7 are regulated in experimental autoimmune encephalomyelitis. Brain 121:159-166.

Kuno K, Kanada N, Nakashima E, Fujiki F, Ichimura F, Matsushima K (1997) Molecular cloning of a gene encoding a new type of metalloproteinase-disintegrin family protein with thrombospondin motifs as an inflammation associated gene. J Biol Chem 272:556-562.

Landolt RM, Vaughan L, Winterhalter KH, Zimmermann DR (1995) Versican is selectively expressed in embryonic tissues that act as barriers to neural crest cell migration and axon outgrowth. Development 121:2303-2312.

Lark MW, Bayne EK, Lohmander LS (1995a) Aggrecan degradation in osteoarthritis and rheumatoid arthritis. Acta Orthop Scand Suppl 266:92-97.

Lark MW, Gordy JT, Weidner JR, Ayala J, Kimura JH, Williams HR, Mumford RA, Flannery CR, Carlson SS, Iwata M, Sandy JD (1995b) Cell-mediated catabolism of aggrecan. Evidence that cleavage at the "aggrecanase" site (Glu373-Ala374) is a primary event in proteolysis of the interglobular domain. J Biol Chem 270:2550-2556.

Lark MW, Williams H, Hoernner LA, Weidner J, Ayala JM, Harper CF, Christen A, Olszewski J, Konteatis Z, Webber R (1995c) Quantification of matrix metalloproteinase-generated aggrecan G1 fragment using monospecific anti-peptide serum. Biochem J 307:245-252.

Lark MW, Bayne EK, Flanagan J, Harper CF, Hoerrner LA, Hutchinson NI, Singer II, Donatelli SA, Weidner JR, Williams HR, Mumford RA, Lohmander LS (1997) Aggrecan degradation in human cartilage. Evidence for both matrix metalloproteinase and aggrecanase activity in normal, osteoarthritic, and rheumatoid joints. J Clin Invest 100:93-106.

Lemons ML, Howland DR, Anderson DK (1999) Chondroitin sulfate proteoglycan immunoreactivity increases following spinal cord injury and transplantation. Exp Neurol 160:51-65.

Li H, Domowicz M, Hennig A, Schwartz NB (1996) S103L reactive chondroitin sulfate proteoglycan (aggrecan) mRNA expressed in developing chick brain and cartilage is encoded by a single gene. Brain Res Mol Brain Res 36:309-321.

Matthews RT, Gary SC, Zerillo C, Pratta M, Solomon K, Arner EC, Hockfield S (2000) Brain-enriched hyaluronan binding (BEHAB)/ Brevican cleavage in a glioma cell line is mediated by a disintegrin and metalloproteinase with thrombospondin motifs (ADAMTS) family member. J Biol Chem 275:22695-22703.

Meyer-Puttlitz B, Milev P, Junker E, Zimmer I, Margolis RU, Margolis RK (1995) Chondroitin sulfate and chondroitin/keratan sulfate proteoglycans of nervous tissue: developmental changes of neurocan and phosphacan. J Neurochem 65:2327-2337.

Meyer-Puttlitz B, Junker E, Margolis RU, Margolis RK (1996) Chondroitin sulfate proteoglycans in the developing central nervous system. II. Immunocytochemical localization of neurocan and phosphacan. J Comp Neurol 366:44-54

Milev P, Chiba A, Haring M, Rauvala H, Schachner M, Ranscht B, Margolis RK, Margolis RU (1998a) High affinity binding and overlapping localization of neurocan and phosphacan/protein-tyrosine phosphatase-zeta/beta with tenascin-R, amphoterin, and the heparinbinding growth-associated molecule. J Biol Chem 273:6998-7005.

Milev P, Maurel P, Chiba A, Mevissen M, Popp S, Yamaguchi Y,
Margolis RK, Margolis RU (1998b) Differential regulation of expression of hyaluronan-binding proteoglycans in developing brain: aggrecan, versican, neurocan, and brevican. Biochem Biophys Res Commun 247:207-212.

Mort JS, Magny MC, Lee ER (1998) Cathespin B: an alternative protease for the generation of an aggrecan "metalloproteinase" cleavage neoepitope. Biochem J 335:491-494.

Oakley RA, Tosney KW (1991) Peanut agglutination and chondroitin6-sulfate are molecular markers for tissues that act as barriers to axon advance in the avian embryo. Dev Biol 147:187-206.

Oakley RA, Lasky CJ, Erickson CA, Tosney KW (1994) Glycoconjugates mark a transient barrier to neural crest migration in the chicken embryo. Development 120:103-114

Olsson L, Stigson M, Perris R, Sorrell JM, Lofberg J (1996) Distribution of keratin sulphate and chondroitin sulphate in wild type and white mutant axolotl embryos during neural crest cell migration. Pigment Cell Res 9:5-17.

Pagenstecher A, Stalder AK, Kincaid CL, Shapiro SD, Campbell IL (1998) Differential expression of matrix metalloproteinase and tissue inhibitor of matrix metalloproteinase genes in the mouse central nervous system in normal and inflammatory states. Am J Pathol 152:729-741.

Perris R, Krotoski D, Lallier T, Domingo C, Sorrell JM, Bronner-Fraser M (1991) Spatial and temporal changes in the distribution of proteoglycans during avian neural crest development. Development 111:583-599.

Pettway Z, Guillory G, Bronner-Fraser M (1990) Absence of neural crest cells from the region surrounding implanted notochords in situ. Dev Biol 142:335-345.

Pettway Z, Domowicz M, Schwartz NB, Bronner-Fraser M (1996) Agedependent inhibition of neural crest migration by the notochord correlates with alterations in the S103L chondroitin sulfate proteoglycan. Exp Cell Res 225:195-206.

Plaas AH, West LA, Wong-Palms S, Nelson FR (1998) Glycosaminoglycan sulfation in human osteoarthritis. Disease-related alterations at the non-reducing termini of chondroitin and dermatan sulfate. J Biol Chem 273:12642-12649.

Rauch U, Gao D, Janetzko A, Flaccus A, Hilgenberg L, Tekotte H, Margolis RK, Margolis RU (1991) Isolation and characterization of developmentally-regulated chondroitin sulfate and chondroitin/keratan sulfate proteoglycans of brain identified with monoclonal antibodies. J Biol Chem 266:14785-14801.

Rauch U, Karthikeyan L, Maurel P, Margolis RU, Margolis RK (1992) Cloning and primary structure of neurocan, a developmentally regulated, aggregating chondroitin sulfate proteoglycan of brain. J Biol Chem 267:19536-19547.

Rauch U, Clement A, Retzler C, Frohlich L, Fassler R, Gohring W, Faissner A (1997) Mapping of a defined neurocan binding site to distinct domains of tenascin-C. J Biol Chem 272:26905-26912.

Risling M, Fried K, Linda H, Carlstedt T, Cullheim S (1993) Regrowth of motor axons following spinal cord lesions: distribution of laminin and collagen in the CNS scar tissue. Brain Res Bull 30:405-414.

Romanic AM, White RF, Arleth AJ, Ohlstein EH, Barone FC (1998) Matrix metalloproteinase expression increases after cerebral focal ischemia in rats: inhibition of matrix metalloproteinase- 9 reduces infarct size. Stroke 29:1020-1030.

Rosenberg GA (1995) Matrix metalloproteinases in brain injury. J Neurotrauma $12: 833-842$

Salmivirta M, Lidholt K, Lindahl U (1996) Heparan sulfate: a piece of information. FASEB J 10:1270-1279.

Sandy JD, Lark ML (1999) Proteolytic degradation of normal and osteoarthritic cartilage matrix. In: Osteoarthritis (Brandt KD, Doherty M, Lohmander SL, eds), pp 84-93. Oxford UP.

Sandy JD, Verscharen C (2001) Western analysis of aggrecan in normal, acutely injured and late stage osteoarthritic human knee cartilage and synovial fluid indicates that aggrecanase (ADAMTS) activity is responsible for functional destruction of aggrecan whereas MMP-like activity is responsible for non-destructive aggrecan cleavage. Biochem $\mathrm{J}$, in press.

Sandy JD, Boynton RE, Flannery CR (1991) Analysis of the catabolism of aggrecan in cartilage explants by quantitation of peptides from the three globular domains. J Biol Chem 266:8198-8205.

Sandy JD, Flannery CR, Neame PJ, Lohmander LS (1992) The structure of aggrecan fragments in human synovial fluid. Evidence for the involvement in osteoarthritis of a novel proteinase which cleaves the Glu 373-Ala 374 bond of the interglobular domain. J Clin Invest 89:1512-1516.

Sandy JD, Plaas AH, Koob TJ (1995) Pathways of aggrecan processing in joint tissues. Implications for disease mechanism and monitoring. Acta Orthop Scand Suppl 266:26-32.

Sandy JD, Gamett D, Thompson V, Verscharen C (1998) Chondrocytemediated catabolism of aggrecan: aggrecanase-dependent cleavage induced by interleukin-1 or retinoic acid can be inhibited by glucosamine. Biochem J 335:59-66.

Sandy JD, Thompson V, Doege K, Verscharen C (2000) The interme- 
diates of aggrecanase-dependent cleavage of aggrecan in rat chondrosarcoma cells treated with interleukin-1. Biochem J 351:161-166.

Sandy JD, Westling J, Kenagy KD, Iruela-Arispe ML, Verscharen C, Rodriguez-Mazaneque JC, Zimmerman DR, Lemire JM, Fischer JW, Wight TN, Clowes AW (2001) Versican V1 proteolysis in human aorta in vivo occurs at the Glu 441-Ala 442 bond, a site that is cleaved by recombinant ADAMTS-1 and ADAMTS-4. J Biol Chem 276:1337213378.

Schwartz NB, Hennig AK, Krueger Jr RC, Krzystolik M, Li H, Mangoura D (1993) Developmental expression of S103L cross-reacting proteoglycans in embryonic chick. Prog Clin Biol Res 383B:505-514.

Schwartz NB, Domowicz M, Krueger Jr RC, Li H, Mongoura D (1996) Brain aggrecan. Perspect Dev Neurobiol 3:291-306.

Schwartz NB, Pirok EW I, Mensch Jr JR, Domowicz MS (1999) Domain organization, genomic structure, evolution, and regulation of expression of the aggrecan gene family. Prog Nucleic Acid Res Mol Biol 62:177-225.

Seidenbecher CI, Gundelfinger ED, Bockers TM, Trotter J, Kreutz MR (1998) Transcripts for secreted and GPI-anchored brevican are differentially distributed in rat brain. Eur J Neurosci 10:1621-1630.

Snow DM, Letourneau PC (1992) Neurite outgrowth on a step gradient of chondroitin sulfate proteoglycan (CS-PG). J Neurobiol 23:322-336.

Snow DM, Lemmon V, Carrino DA, Caplan AI, Silver J (1990) Sulfated proteoglycans in astrologlial barriers inhibit neurite outgrowth in vitro. Exp Neurol 109:111-130.

Snow DM, Watanabe M, Letourneau PC, Silver J (1991) A chondroitin sulfate proteoglycan may influence the direction of retinal ganglion cell outgrowth. Development 113:1473-1485.

Snow DM, Brown EM, Letourneau PC (1996) Growth cone behavior in the presence of soluble chondroitin sulfate proteoglycan (CSPG), compared to behavior on CSPG bound to laminin or fibronectin. Int J Dev Neurosci 14:331-349.

Steindler DA, O'Brien TF, Laywell F, Harrington K, Faissner A, Schachner M (1990) Boundaries during normal and abnormal brain development: in vivo and in vitro studies of glia and glycoconjugates. Exp Neurol 109:35-56.

Sztrolovics R, Alini M, Roughley PJ, Mort JS (1997) Aggrecan degradation in human intervertebral disc and articular cartilage. Biochem $\mathrm{J}$ 326:235-241.

Tortorella MD, Burn TC, Pratta MA, Abbaszade I, Hollis JM, Liu R, Rosenfeld SA, Copeland RA, Decicco CP, Wynn R, Rockwell A, Yang F, Duke JL, Solomon K, George H, Bruckner R, Nagase H, Itoh Y, Ellis DM, Ross H, Wiswall BH, Murphy K, Hillman MCJ, Hollis GF, Arner EC (1999) Purification and cloning of aggrecanase-1: a member of the ADAMTS family of proteins. Science 284:1664-1666.

Tortorella MD, Pratta M, Liu RQ, Austin J, Ross OH, Abbaszade I, Burn T, Arner E (2000) Sites of aggrecan cleavage by recombinant human aggrecanase-1 (ADAMTS-4). J Biol Chem 275:18566-18573.

Wilson MT, Snow DM (2000) Chondroitin sulfate proteoglycan expression pattern in hippocampal development: potential regulation of axon tract formation. J Comp Neurol 424:532-546.

Yamada H, Watanabe K, Shimonaka M, Yamasaki M, Yamaguchi Y (1995) cDNA cloning and the identification of an aggrecanase-like cleavage site in rat brevican. Biochem Biophys Res Commun 216:957-963.

Yamada H, Fredette B, Shitara K, Hagihara K, Miura R, Ranscht B, Stallcup WB, Yamaguchi Y (1997) The brain chondroitin sulfate proteoglycan brevican associates with astrocytes ensheathing cerebellar glomeruli and inhibits neurite outgrowth from granule neurons. J Neurosci 17:7784-7795.

Yamaguchi Y (1996) Brevican: a major proteoglycan in adult brain. Perspect Dev Neurobiol 3:307-317.

Yamaguchi Y (2000) Lecticans: organizers of the brain extracellular matrix. Cell Mol Life Sci 57:276-289.

Zaremba S, Guimaraes A, Kalb RG, Hockfield S (1989) Characterization of an activity-dependent, neuronal surface proteoglycan identified with monoclonal antibody Cat-301. Neuron 2:1207-1219. 